\title{
pro.posıções
}

http://dx.doi.org/10.1590/1980-6248-2018-0021

ARTIGOS

\section{Professores no Facebook: explorações sobre a gestão da distância e da proximidade diante do público escolar ${ }^{1}$}

\section{Teachers on Facebook: explorations on distance and proximity management faced by school audience}

Tiago Ribeiro Santos (i)

Ione Ribeiro Valle (ii)

(i) Fundação Universidade Regional de Blumenau - FURB, Blumenau, SC, Brasil. http://orcid.org/0000-0002-0941-167X, tiagoribeiro@furb.br.

(ii) Universidade Federal de Santa Catarina - UFSC, Florianópolis, SC, Brasil. http://orcid.org/00000001-7496-3959, ione.valle@ufsc.br.

\section{Resumo:}

A presença de redes sociais virtuais nas interações entre professores e alunos permite interrogar o trabalho coletivo de gestão da proximidade e da distância. A partir de registros orais de professores extraídos de um videodocumentário, se procura compreender aqui práticas de gestão das relações escolares no Facebook. Os relatos são analisados à luz de duas categorias de análise que, organizadas de modo a apreender situações cotidianas, reúnem as impressões que os professores apresentam quando discorrem sobre o uso do Facebook. A primeira aponta para o que nomeamos aqui de "ajuntamento de círculos sociais diferenciados", permitindo reconhecer a singularidade de um espaço como o Facebook com relação à gestão da proximidade e da distância do professor diante do público escolar. A segunda se distingue pelas "condições técnicas de discrição", sinalizando margens de manobras de que os professores podem se servir na rede social on-line, estabelecendo uma forma ideal de interação com seus alunos. Estas categorias resultam em uma realidade em que os professores gestam tanto suas relações com o público escolar (e com a tecnologia) quanto suas imagens pessoais e os possíveis (des)créditos educacionais vinculados a elas.

Palavras-chaves: gestão da imagem, redes sociais, papel de professor, moral, Goffman

\footnotetext{
${ }^{1}$ Normalização, preparação e revisão textual: Douglas Mattos (Tikinet) - revisao@tikinet.com.br
} 


\begin{abstract}
:
The presence of social medias in teacher-student interactions raises questions on the collective work of managing proximity and distance. From teachers' testimonies extracted from a video documentary we sought to understand practices of management of school interactions on Facebook. The reports are analyzed in the light of two categories of analysis that, organized to apprehend everyday situations, gather the impressions teachers have when discussing Facebook use. The first one points to what we have called the "gathering of differentiated social circles", allowing us to recognize the uniqueness of a space such as Facebook in relation to the management of proximity and the distance of the teacher from the school public. The second is distinguished by the "technical conditions of discretion," signaling margins of maneuvers teachers can use on the online social network, establishing an ideal form of interaction with their students. These categories result in a reality in which teachers manage both their relationships with the school audience (and technology) as well as their personal images and the possible educational (dis)credits associated with them.
\end{abstract}

Keywords: image management, social networks, teacher role, Goffman

\title{
Introdução
}

A ideia de que as relações entre professores e alunos se estabelecem dentro de certos limites de distância ou de proximidade é bastante antiga. Na Idade Média, por exemplo, segundo escreve Léo Moulin (1994, p. 225), era comum que “os contatos dos alunos com o mestre, que os chamava de seus 'familiares' ou 'da família' porque alguns habitavam na mesma casa do professor, fossem íntimos e diretos. Viviam sob o mesmo teto, iam juntos aos ofícios ou à taberna". A invenção da escola moderna, por sua vez, supôs uma separação entre o professor e esses ambientes aleatórios, conferindo um lugar mais preciso às relações pedagógicas. A escola como um lugar oficial de encontros entre professores e alunos condicionou, consequentemente, novas formas de coerção coletiva, tais como as da corporação de mestres que podiam julgar in loco o ensino que estava sendo dado pelo professor, fazendo avaliações, reprimendas etc. (Durkheim, 1938). A história da educação, nesta perspectiva, poderia ser entendida também como uma longa história das separações, prevendo a existência não apenas de uma linha demarcatória entre os professores e seus alunos, mas também de trabalhos coletivos de gestão da distância e da proximidade que definem relações educacionais. 


\section{pro.posıções}

http://dx.doi.org/10.1590/1980-6248-2018-0021

O curioso é que, diante desse aspecto dramático da educação, autores como Goffman tenham ocupado uma posição menor se comparada a de sociólogos igualmente clássicos como Durkheim, Elias e Bourdieu. A razão de sua tímida influência não é simples, mas isso não impede que ela seja indicada. A título de educação, apenas raras linhas de Goffman trataram das relações escolares, embora obras como Asylums e Stigma condicionem problematizações sobre internatos escolares (Benelli, 2003; Guige \& Boulin, 2016), assim como inclusão social e educação especial (Freund \& Biar, 2017; Schilling \& Miyashiro, 2008)². Goffman, porém, não deixava de se servir de outras pesquisas que envolviam o papel de professor a fim de administrar as provas de seus conceitos - como se pode ver no seguinte trecho, em The presentation of self in everyday life (A representação do eu na vida cotidiana):

O ator prudente tentará selecionar a espécie de plateia que cause o mínimo de dificuldades, em termos do espetáculo que deseja encenar e do espetáculo que não deseja ter de apresentar. Assim diz-se que os professores frequentemente não gostam dos alunos iniciantes nem dos pertencentes às últimas séries, porque ambos os grupos podem tornar difícil manter na sala de aula o tipo de definição de situação que reafirma o papel profissional do professor (Goffman, 2002, p. 236).

As situações escolares são - conforme o trecho citado - compostas de plateias mais ou menos oficiais que atuam sobre o comportamento do professor. A obra de Goffman pode ser, entretanto, apreendida sobre um aspecto menos coercitivo se avançarmos sobre outros trabalhos como Encounters, em que a noção de role distance traduz a astúcia do autor em supor indivíduos capazes de relativizar seus próprios papeis sociais a partir de diferentes formas de definição da situação. Esta suporia um indivíduo capaz de atuar diferentemente segundo suas formas de enquadramento da realidade, autorizando-se ao mesmo tempo a flexibilizar seu papel ante as mais diversas contingências. O papel de professor, em termos goffmanianos, assim pode ser relativizado quando um professor, sem ser coagido pela sua plateia, encontra margens de manobra para exprimir suas virtudes de ator social ${ }^{3}$.

\footnotetext{
${ }^{2}$ Estas obras de Goffman tendem a apresentar um lado mais "trágico" de sua perspectiva, em que predominam situações embaraçosas, constrangedoras, difíceis. A epígrafe de Stigma é exemplar à medida que apresenta uma jovem, que se exprime através de uma carta, lastimando sobre sua deformação facial a ponto de se interrogar se não deveria cometer um suicídio.

${ }^{3}$ Esta característica provavelmente condicionaria também a análise de nomes como Platão, Boécio, Abelardo etc., que eventualmente se deparavam com estruturas sociais hostis às suas formas de ensino. Rouche (1981) lança mão dessa estratégia, compreendendo que o "objetivo fundamental da educação, de dominar os desejos, apenas pode ser atingido em função de voluntária adesão da estrutura educativa" (p. 667).
} 


\section{pro.posições}

http://dx.doi.org/10.1590/1980-6248-2018-0021

$e$-ISSN 1980-6248

A modernidade é, afinal, também sinônimo de abertura, de modo que atuar como professor significa atuar através de apenas um entre muitos outros papeis sociais que compõem a vida de um indivíduo. Este ora frui de prazeres da vida contemporânea que não se reduzem à escola, tais como lazeres culturais e esportivos, manifestações políticas, momentos em família e “embalos de sábados à noite”. A vida social moderna supõe aí um caráter contingente, diverso e também democrático, deslocando a imagem de professor de uma situação oficial (escolar) para outras (familiares, culturais, festivas) que provavelmente não requereriam comportamentos como a explicação de uma equação ou uma fala polida e despojada de gírias usadas entre amigos. A questão de onde começam e onde terminam as "relações de professor" parece surgir justamente aí quando um professor atua fora dos limites da escola, embora continue sujeito à observação de seu público de alunos, diretores, secretários etc.

Esta situação deslocada em que se pode encontrar um professor é que será abordada aqui a partir de uma análise das condições interacionais oferecidas pelos meios tecnológicos de comunicação. Estes meios não seriam, afinal, espaços de comunicação que abstraem circunstâncias escolares sem necessariamente impedir contatos entre professores e alunos? A análise de espaços de interação virtual como o Facebook é justamente uma forma de encontrar outras circunstâncias, limites e posicionamentos que podem tornar uma relação educacional possível em espaços não institucionais. O Facebook, a partir desta perspectiva, pode ser interrogado não apenas em termos de "encontros" - às vezes trágicos, tais como a circulação de uma foto de um professor em estado ébrio, ou "proibidos", como nos Estados Unidos, onde as escolas impõem regras do uso do Facebook a fim de impedir possíveis assédios ("Professora é demitida", 2017) -, mas também como um espaço de (re)definição do lugar do professor ante seu público escolar.

A essa (re)definição se soma a questão de que, se as relações pedagógicas são também relações morais, os professores tendem a manter compromisso com suas próprias imagens pessoais. As relações de proximidade e distância tão logo podem se tornar verdadeiros dramas cotidianos à medida que colocam esta imagem em questão. Estes dramas é que talvez suponham um professor não apenas preocupado com o que diz respeito ao ensino-aprendizagem, mas ao que suas imagens podem dizer sobre ele mesmo, levando-o a controlar as possíveis impressões que ele produziria em seus alunos através do Facebook. A questão, portanto, torna-se menos sobre gestar as impressões dos alunos do que gestar suas próprias expressões de professor, 
evitando situações virtualmente problemáticas como fotos em trajes de banho, consumindo bebidas alcoólicas ou curtindo conteúdos sui generis.

\section{Perspectiva metodológica: exame de um registro pré-existente}

A gestão da proximidade e da distância, conforme exposto até aqui, pode ser considerada um fenômeno macrossocial, de modo que ele pode ser observado em diversos contextos: escolas públicas, privadas, no nosso país e em outros. No Brasil, por sua vez, forçoso seria não reconhecer que, no âmbito das políticas públicas em educação, o uso das redes sociais on-line permanece uma questão indefinida - ainda que um projeto de lei já tenha tentado normatizá-la ("Projeto de Lei”, 2015). A fim de explorar resoluções deixadas consequentemente a cargo da comunidade escolar, este artigo se serve de um documentário em que professores do Ensino Médio de um colégio estadual da região de Jacarepaguá (RJ) apresentam diferentes situações quanto ao uso do Facebook com seus alunos ${ }^{4}$.

A análise de um registro pré-existente, ou seja, dos relatos orais dos professores interpelados, requer precisas posturas metodológicas. A quais critérios de validação científica estaria sujeita, por exemplo, a fala de professores que respondem a perguntas que não foram realizadas pelo próprio autor deste artigo? A questão aqui, diante deste obstáculo, não se trata de entender as motivações que produzem os testemunhos dos professores abordados, mas de observá-los se situando contra ou a favor das impressões que têm com relação ao Facebook. A fim de dar sentido aos testemunhos recolhidos, independentemente de suas motivações, convém se deter ao que Goffman (1959) chamava de "quadro primário": um equipamento mental ativado, visando compreender situações que têm lugar em dado ambiente e que, assim, auxilia os professores a organizar suas experiências, gerindo suas relações.

Os quadros primários, diferenciando-se de acordo com as experiências cotidianas dos professores, contêm realidades que não seriam nem verdadeiras nem falsas, mas que poderiam ser deduzidas como plausíveis no espaço do Facebook. Estas realidades, não sem exagero, talvez falem do que há de mais cotidiano nesse espaço virtual e que, por sua vez, apenas parecem

\footnotetext{
4 O documentário Uma escola entre redes busca "compreender o cotidiano de utilização das redes sociais por professores e estudantes de Ensino Médio” de um colégio estadual da cidade do Rio de Janeiro. (Carrano, 2013, s. p.).
} 


\section{pro.posıções}

http://dx.doi.org/10.1590/1980-6248-2018-0021

$e$-ISSN 1980-6248

factíveis quando levam em conta as situações comuns vividas pelos professores. À maneira de Erving Goffman, que se servia de um amplo repertório de ilustrações para administrar suas provas - trechos de romances, notícias de jornais, laudos médicos etc. (Manning, 1992) -, servir-se do documentário se trata de uma aposta metodológica para ilustrar realidades do cotidiano de professores. Os professores, ora representando a si mesmos no vídeo, representam também uma imagem pública da situação da relação entre escola e Facebook.

A sociologia do cotidiano manifesta, assim, seu compromisso com as realidades não apenas comuns, mas publicamente acessíveis. A fim de enfatizar a natureza das interações virtuais cujos diferentes públicos vivenciam, convém então, ainda que genericamente, tratar das relações entre "lugar" e "espaço" que podem ser aplicadas ao Facebook. A obra de Goffman, para tanto, será acionada, ao mesmo tempo que inflexionada, de modo que as interações na internet possam assumir uma perspectiva que não oponha a realidade à virtualidade... ou a escola ao Facebook.

\section{O lugar e o espaço (ou a natureza das interações virtuais em termos situacionais)}

As redes sociais on-line sem dúvida conquistaram a vida cotidiana de uma parte não negligenciável de indivíduos. Os seus inúmeros fins logo exigem da sociologia uma teorização capaz de aprender formas elásticas e dinâmicas de utilização. As palavras de Weber (2003) sobre ciências "dotadas de eterna juventude", como seria o caso "de todas as disciplinas históricas, de todas aquelas para as quais o fluxo constantemente progressivo da cultura continuamente suscita novos problemas" (p. 120), parecem soar aí mais forte do que nunca. Os cientistas veem-se quase obrigados a realizar um vai e vem entre textos clássicos e contemporâneos a fim de contribuir para a renovação da imaginação sociológica. O que teria a dizer Goffman (1959), por exemplo, sobre a internet em que "fachadas" pessoais se multiplicam e colocam em cena complexos aparatos expressivos dispostos a impressionar uma plateia que assiste a tudo isso de um lugar aparentemente distante?

A leitura de sua obra parece urgente em contextos virtuais em que as interações se tornam constantes e se iniciam e se interrompem à margem da etiqueta cotidiana, afinal, um e-mail não respondido é muito mais comum que uma pergunta que se deixa cair no "vazio" em 


\section{pro.posıções}

http://dx.doi.org/10.1590/1980-6248-2018-0021

$e$-ISSN 1980-6248

contatos face a face. Estas situações, analisadas do ponto de vista goffmaniano - tão comuns a ponto de quase não serem mais interrogadas -, talvez permitam desfazer de imediato certos mal-entendidos acerca do suposto fim da "vida privada" na internet. A noção de "bastidor", por exemplo, permite evitar possíveis pânicos morais relativos a uma sociedade de transparência à medida que prevê uma região segregada da observação coletiva (Aspling, 2011), onde ocorre a preparação de uma performance ${ }^{5}$. Esta região privada - porque priva um público da presença de outro - não seria também aquela que permite que alguém escolha e edite minuciosamente uma foto antes de fazer a publicação? Os usuários podem, graças a essa região, omitir informações como postos de trabalho de baixo prestígio, idade, situações amorosas instáveis e, em contrapartida, privilegiar outras como grau acadêmico, gostos musicais, hábitos esportivos etc., visando expressar valores capazes de produzir impressões mais ou menos previsíveis ou desejadas. Estes usuários estariam, assim, definindo seus próprios eus com relação aos outros sem que suas vidas privadas fossem sentidas como violadas apesar do uso intensivo e ostensivo da internet. Os indivíduos, gestando suas próprias expressões, estariam operando - ainda em termos goffmanianos - a representação do eu na vida cotidiana e igualmente se socializando em função de uma transação contínua consigo mesmo e com o outro.

O legado de Goffman tem, entretanto, seus limites. Goffman lembrava, desde as primeiras páginas de The presentation of self, que sua perspectiva se aplicava principalmente à análise de interações ocorridas em estabelecimentos físicos - em lugares constituídos de barreiras de percepções, paredes, muros etc., vistos como elementos fundamentais à definição de uma situação social ou de um contexto de indivíduos observadores e observados (Smith, 2006). Goffman privilegiava então momentos que seriam, em suma, efeitos de interações presenciais e face a face. Estes momentos tenderiam a permanecer em transação constante na forma de um vai e vem de expressões e impressões geradas pelos indivíduos (Burns, 1992). O sociólogo estabelecia, enfim, um modo de análise compreendendo a representação do eu em relação aos momentos, casuais ou solenes, que fariam parte da experiência da vida cotidiana e moderna.

\footnotetext{
${ }^{5}$ A definição de performance no pensamento de Goffman prevê um comportamento ou uma atividade em que uma pessoa se apresenta a uma audiência. A performance conta aí com atores sociais que criam impressões de si mesmos para determinado público, seja facilitando sua interação com ele, seja estabelecendo ou transformando sua forma de identificação (Jacobsen \& Kristiansen, 2014).
} 


\section{pro.posıções}

http://dx.doi.org/10.1590/1980-6248-2018-0021

O apoio de Giddens (1996) a estes limites goffmanianos nos parece essencial, considerando que a separação entre o "aqui" e o "agora" corresponde a uma entre outras "características distintivas da modernidade". O aqui como um lugar e o agora como um tempo, em Goffman, estavam fortemente vinculados, prevendo um campo autônomo de análise chamado de "ordem da interação". Giddens (1996), por sua vez, atento às dinâmicas de estruturação das sociedades modernas, contemplava um desencaixe entre o aqui e o agora que possibilitaria interações não mais dependentes de indivíduos engajados em situações de copresença. O resultado da mesma separação consistiria, mais nitidamente, numa transformação da condição interacional que não exigiria mais um contexto localmente comum para que os indivíduos se engajassem em uma mesma situação. Essa condição é que permitirá redirecionar a sensibilidade goffmaniana para as interações ocorridas fora de lugares, ou que mais à frente poderiam ser chamadas de extrainstitucionais ${ }^{6}$.

Goffman, entretanto, supôs indivíduos cujas habilidades e agilidades de raciocínio poderiam servir como meios reparadores de situações que poderiam ser sempre perturbadas. A modernidade seria, pois, um palco de contingências, de interações feitas e desfeitas cotidianamente. As dificuldades em "manter a cena" poderiam representar, assim, sempre desafios de maior monta. Estas contingências é que autorizam os indivíduos a (re)elaborar suas condições interacionais em vista de construir um contexto comum - desfeito pela separação anteriormente mencionada - cujo exemplo se expressa na pergunta ao telefone: "será que você pode falar agora?". Goffman e sua atenção aos pequenos protocolos cotidianos, como essa pergunta, permite abordar outros tipos de situações em que diferentes convenções coletivas atuariam em vista de estabelecer certa ordem de interação ${ }^{7}$.

\footnotetext{
${ }^{6}$ A tensão em termos de lugar e de espaço tende a ocorrer, principalmente, quando ambos se vinculam a uma pessoa através da imagem de seu rosto. As notas de Elias (1994) sobre a "moldagem facial como exemplo da peculiaridade da individualização humana" (p. 160) contribui com a definição do rosto como uma imagem de caráter insubstituível, indistinguível e autêntico. Esta mesma condição é que faz do rosto um atributo central da pessoa, que pode ser tanto valorizado em fotos no estilo selfies na internet quanto escondido em casos de situações constrangedoras, melhor representadas pelas reportagens policiais. Os nicknames utilizados em sites de risco - como de relações extraconjugais - podem ser vistos assim como uma forma de proteger sua pessoa através de um avatar. ${ }^{7}$ Martuccelli (1999), ao situar a obra de Goffman e de Giddens em uma das matrizes da modernidade chamada de "condição moderna", sublinha essa instabilidade permanente na forma de uma busca pela solidez em espaços de constante fluidez como se parafraseasse Marx, dizendo que "tudo que é sólido se desmancha no ar". Os meios individuais e modernos de comunicação poderiam ser considerados uma entre essas formas capazes de ordenar interações sociais, mas também de colocá-las em colapso em um só segundo, como seria o caso do vazamento de uma informação sigilosa ou de uma foto comprometedora.
} 


\section{pro.posıções}

http://dx.doi.org/10.1590/1980-6248-2018-0021

$e$-ISSN 1980-6248

As tecnologias de comunicação trouxeram, assim, às interações sociais uma elasticidade singular, condicionando um jogo de impressões e expressões independentes das copresenças locais, mas não independentes de certa ordem. O maior exemplo dessa elasticidade está no fato de ter criado condições interacionais menos sujeitas às coerções do lugar, uma vez que suas qualidades portáteis - como um telefone sem fio - permitem que uma conversa se desloque do campo de visão e audição coletiva de uma sala de estar para a privacidade de um quarto. As virtudes da portabilidade dos meios pessoais de comunicação livraram relativamente os indivíduos da observação de um público que poderia influenciar o que eles estariam dizendo para alguém do outro lado da linha. Esta condição interacional é que oportuniza novas performances - como a de uma quadrilha de golpistas que, atuando no interior de uma prisão, liga para famílias com parentes hospitalizados se passando por médicos e solicitando dinheiro para compra de remédios (“Presos fingem”, 2017).

As formas de controle social, enfim, afrouxam-se do ponto de vista de um público observador que tende a desaparecer das interações, que passam a ser sustentadas através de performances derivada dos lugares mais inesperados e, por isso, também silenciosos e discretos de comunicação. As regiões, os lugares, os territórios etc. podem se tornar, portanto, cada vez menos uma condição indispensável à existência de interações à medida que elas podem ocorrer em "espaços" (Giddens, 1996) como uma rede de e-mails, de telefones ou de páginas no Facebook. Estes dependem apenas de uma conexão via internet e de um dispositivo técnico e por isso podem ser vistos como espaços sem lugar preciso, à medida que podem estar em pleno funcionamento mesmo em reuniões de negócios importantes ou durante as aulas na universidade, seja desviando o foco de uma interação presencial ou a serviço da própria situação oficial (como um auxílio à captura de informações consideradas pertinentes àquele contexto). Os lugares passam, assim, a ser coabitados pelos espaços (e vice-versa), e é essa coabitação que convém sublinhar para que se tornem evidentes relações dinâmicas entre um lugar chamado escola e um espaço chamado Facebook.

Estas dinâmicas às vezes podem ser observadas através de desarranjos do tempo de trabalho em que indivíduos podem se mostrar receptivos (ou vulneráveis à recepção) a tarefas antes obstruídas pelas distâncias físicas. Estas desobstruções iniciais acerca da relação é que tornam comum o fato de regressarmos de um período de férias e, ao abrirmos nossa caixa de e-mails, depararmo-nos com um acúmulo de mensagens que aguardam resposta. $\mathrm{O}$ que isso quer dizer é que, apesar de ausentes, estivemos sempre presentes graças a esse espaço por meio 


\section{pro.posıções}

http://dx.doi.org/10.1590/1980-6248-2018-0021

de uma rede de e-mails, que é indiferente tanto ao tempo quanto à sinuosidade de caminhos e à diversidade de lugares que eventualmente percorremos na vida cotidiana. $\mathrm{O}$ mesmo se poderia dizer, com ressalvas, sobre as caixas de correios que se abarrotam de correspondências quando partimos de férias e que, como as caixas de e-mails, supõem-se mais ou menos frequentadas pelos seus usuários.

As duas caixas de correspondência, uma situada em um "lugar" e outra em um "espaço", têm, entretanto, uma diferença essencial. Esta última aceita que possamos verificá-la mesmo quando não estamos em casa. Os indivíduos podem ser encontrados em um endereço independentemente de suas próprias mobilidades. Este seria o caso de um médico que poderia receber através de seu telefone celular um chamado de urgência ao mesmo tempo em que se encontra em sua casa de praia, com sua família, em uma manhã de domingo. O resultado da separação entre o aqui e o agora não seria, portanto, outro senão o de produzir interações tanto localmente dissituadas quanto espacialmente ressituadas, à medida que aquele médico contextualiza sua situação, e é isso o que condicionará ou não o atendimento da emergência. A ressituação de uma interação em dado espaço é que permite prever uma série de esforços colocados em prática pelos indivíduos em vista de definir o que está se passando entre eles.

A questão de como um professor pode (re)situar sua relação com seus alunos em outro espaço, diferente da escola, a partir do que foi exposto até aqui, surge com um problema próprio das interações virtuais. A problematização do Facebook em termos de "espaço" seria justamente uma forma de compreender essas (re)situações, sem abrir mão de uma tensão permanente com o "lugar", sobretudo à medida que os indivíduos investem seus rostos em suas páginas pessoais. O que convém a seguir é apresentar as características singulares e relativamente invariáveis acerca do tipo de comunicação colocado em funcionamento pelo Facebook. As páginas de Goffman sobre a "representação do eu", assim, somente parecem mais inteligíveis quando relacionadas às margens de manobra oferecidas pela elasticidade do espaço. Esta elasticidade é que torna compreensível, previamente, o porquê de os professores terem experiências tão diversas no Facebook - o que a análise das falas a seguir poderá mostrar. O que importa sublinhar de início é que eles estão, potencialmente, ao menos de início, sujeitos a realizar uma comunicação de "um-para-vários" (Casilli, 2010), e esses “vários" seriam um ajuntamento de círculos sociais diferenciados que caracteriza o ponto de partida da análise que segue. 


\section{pro.posıções}

$e$-ISSN 1980-6248

http://dx.doi.org/10.1590/1980-6248-2018-0021

\section{O ajuntamento de círculos diferenciados}

O item anterior procurou elucidar características gerais de meios pessoais e tecnológicos de comunicação. Estas implicaram uma dissituação local referente às interações sociais e que devem ser somadas, agora, a uma característica mais particular, cujas implicações são provadas pelos professores no Facebook. A questão pode ser resumida em termos de um "deslocamento", uma vez que descentraliza os professores de seus lugares, proporcionando uma condição interacional razoavelmente singular. Este fenômeno pode ser entendido, com ressalvas, a partir do sentido que DaMatta (1997) atribui aos carnavais no Brasil: "momentos mais individualizados, sendo vistos como propriedade de todos e como momentos em que a sociedade se descentraliza" (p. 48). Os carnavais, nesse caso, aparecem marcados pelo uso generalizado de fantasias, pelas quais se supõe que todos podem se apresentar como personagens não previstos pela experiência cotidiana.

O fato é que, diferentemente do Facebook, carnavais são eventos temporal e localmente situados: realizados 40 dias antes da Páscoa e em ruas e clubes da cidade. O Facebook, por sua vez, carece de uma temporalidade e de uma localidade precisas, conforme sua condição de dissituação local. Essa característica permite compreender o porquê desse espaço operar, de início, alargando as dimensões temporais, de modo que a definição de uma situação escolar se torna mais evidente à medida que professor "abraça" seu próprio papel, investindo esforços profissionais também "fora" da escola. Carina, professora de Biologia, no documentário", diz que o Facebook

não deixa de ser uma forma de estar com o aluno no horário em que ele não tá na escola. Porque eles vão embora meio-dia, meio-dia e meia, né, e eu ainda estou aqui, não estou em casa. Mas quando eu chego à noite, a gente ainda consegue estabelecer alguma coisa de data de trabalho, de dúvida perto de prova. Tem aluno que teve algum problema durante a semana e não pôde vir, faltou... e a gente consegue resolver isso. Acho que facilitou, estreitou muito a relação $(14 \mathrm{~m} 56 \mathrm{~s})^{9}$.

Este "estreitamento", ao agrupar professores e alunos em torno de uma mesma espacialidade, apesar de suas diferentes localidades, configura um ajuntamento sem maiores adjetivos. O fato é que o ajuntamento apenas passa a compreender também círculos sociais

\footnotetext{
8 Os nomes das professoras foram aqui intencionalmente modificados, assumindo a forma de pseudônimos escolhidos pelos autores.

${ }^{9} \mathrm{O}$ documentário e as marcações de tempo das falas citadas podem ser conferidos em Carrano (2013).
} 


\section{pro.posições}

http://dx.doi.org/10.1590/1980-6248-2018-0021

diferenciados à medida que Carina avança em suas observações. A rede social é, pois, um espaço onde Carina também "fica sabendo um pouquinho da vida deles" (14m 56s) - o que ela considera "muito importante na relação com o professor" e que dificilmente se daria a ver em situações oficiais de ensino. A proximidade se torna aí condição para o acúmulo de novas impressões, já que - no papel de observadores - os professores podem acessar, mesmo que anonimamente, as páginas de seus alunos. Céu, professora de Geografia, acrescenta detalhes:

entro eventualmente lá, dou uma olhada, e a gente descobre que eles são na verdade às vezes diferente do comportamento que eles têm na sala de aula, né, você vê religião, você vê carinho, você vê rebeldia e então você descobre um outro lado, e ele [o aluno] separado é outro. A gente sabe disso. Você pega um ônibus junto com ele ou bate um papo com ele ali num passeio fora da escola, é outra coisa. Então essa aproximação que a gente faz fora da escola a gente pode fazer também no Facebook (16m 02s).

Estes ajuntamentos, seja o de Carina ou o de Céu, permitem observar que não apenas os laços estreitos são mantidos no interior do Facebook. Os laços, em sentido amplo e efêmero, transitório, também têm seu devido acento, produzindo a sociedade como uma troca dinâmica de expressões e impressões. Estes laços notadamente fugazes, porém, devem contar sempre com uma redução da qualidade dos seus próprios conteúdos. Esta seria a fórmula de Simmel (2006) que, por sua vez, parte do seguinte princípio: indivíduos diferenciados apenas podem encontrar algo em comum entre si à medida que recorrem a conteúdos mais rudimentares, ou seja, conteúdos que possam ser inteligíveis a um número amplo de pessoas apesar de todas as suas diferenças e indiferenças mútuas, como no caso de declarações sobre incidentes cotidianos, selfies, conteúdos risíveis etc. O ordinário é, assim, aquilo que pode pertencer a todos, aquilo que em suma carece de maiores qualidades e que nem por isso deixa de fazer sociedade à medida que é identificado.

Este seria também o caso de "conhecer" o aluno fora da escola, no âmbito de uma espécie de superfície duradoura repleta de oportunidades para se estabelecer sociações. Carina pode assim acrescentar:

Às vezes, a gente consegue numa página do Facebook, numa relação, ter alunos que se aproximam da gente e que não iriam se aproximar se estivessem só no espaço da sala de aula, porque as turmas são muito grandes. A gente acaba estabelecendo contato com alguns, os mais próximos, os mais, né, quem é muito lá pra trás... daí que você consegue chegar lá... Melhora em tudo (16m 45s). 
Simmel (2006) investia em seu construto intelectual aceitando que, mesmo onde o fazer sociedade parece algo impossível, as sociações são sempre possíveis apesar do caráter frágil e fugaz que apresentem. O jornal The New York Times, em 2016, divulgou mudanças previstas pelos desenvolvedores do Facebook em relação aos tipos de conteúdo que seriam privilegiados pelos seus sistemas de algoritmos (Isaac \& Ember, 2016). Os responsáveis pela mudança argumentavam acerca de conteúdos referentes à família e aos amigos que passariam a ser, então, priorizados, ou seja, mais automaticamente exibidos na tela do computador em detrimento de notícias e publicações copiadas de outros sites. Simmel, através de seu constructo intelectual, permite antecipar conceitualmente essa decisão de modo que o Facebook, por sua vez, estaria procurando tornar mais eficaz a tendência que sua própria estrutura já mantinha latente.

O fato é que essa manutenção técnica, que privilegia conteúdos pessoais, apenas faz sentido à medida que expõe conteúdos mais pré-dispostos à sociação. A característica de ajuntar em um só espaço círculos sociais diferenciados pertencentes a um mesmo indivíduo não é uma exclusividade do Facebook. Esse mesmo ajuntamento seria também relativamente possibilitado em eventos como o casamento, o aniversário e o enterro de alguém, que tenderiam a congregar diferentes pessoas de seus círculos de pertencimento, ou seja, de um aqui e agora ligados um ao outro. O que ocorre é que, diferentemente do Facebook, essas ocasiões são excepcionais, extraordinárias, contando com separações nítidas de um mundo cotidiano em que o próprio Facebook não adere de imediato. Estas separações que orientam a vida cotidiana, antes de estarem no Facebook, estão nas próprias definições da realidade operadas pelos professores. Carina, nesse sentido, está propensa a incorporar o espaço do Facebook ao seu próprio papel profissional, dizendo:

acho que nada substitui o espaço da sala de aula, o momento da sala de aula, de estar ali com o aluno naquele momento. Mas eu acho que pode ser um suporte, sim, você ter as redes sociais como... um... um meio, uma forma de você estar com teu aluno, de você estar com ele ali.... Eles passam muito tempo - se eles passam muito tempo, por que eles não podem também passar muito tempo fazendo trabalho, assistindo uma aula, prestando atenção num conteúdo, em alguma coisa, fazendo uma pesquisa... acho que gente pode pensar nisso, $\operatorname{sim}(4 \mathrm{~m} 55 \mathrm{~s})$.

O Facebook, ao desfazer essa separação, condiciona uma realidade em que os papéis sociais não se apoiam necessariamente em uma situação (escolar). O que ocorre é que, ao ocupar o espaço do Facebook, Carina não está necessariamente acompanhada da razão de seu próprio ajuntamento, afinal, o que fazem seus alunos no Facebook pode não se tratar do que eles fazem 


\section{pro.posições}

http://dx.doi.org/10.1590/1980-6248-2018-0021

na escola. A razão do ajuntamento, assim, apenas tenderia a ser restabelecida à medida que os usuários contextualizassem (redefinindo) o que se passa em suas páginas a partir das publicações que fazem. Carina, como outros professores, mais precisamente, apresenta-se através de conteúdos publicados e apreciados pelos seus círculos que, por sua vez, podem aplicar um quadro interpretativo da realidade não necessariamente compartilhado com aqueles primeiros ${ }^{10}$. Carina, por isso, completando, lembra a necessidade de definir regularmente a situação do Facebook na relação escolar:

Primeira vez que eu fiquei um pouquinho receosa, que foi postar trabalho ou então “... façam os exercícios..." eu pensei assim, "isso não vai dar certo", fiquei preocupada. Muito pelo contrário, todo, a maioria, assim, o número de alunos que fizeram foi maior que quando a gente manda. Dou aula de Biologia, então, dou dois tempos, semanais, eu só vou vê-los daqui uma semana... e ficar ali... deixando... "tá ali... postei já... não se esqueçam". A coisa funciona mais. A maioria fez porque tá vendo ali toda hora... (6m 20s)

O que se modifica sensivelmente em um espaço como o Facebook diz respeito, assim, ao acordo entre os indivíduos implicados em dada situação. $\mathrm{O}$ ajuntamento, ao reunir um tipo particular de audiência, tende a forçar os professores a determinar constantemente o que está se passando em suas páginas para seus alunos. Esta condição permite colocar em questão um princípio da Sociologia de Goffman. Esta partia do pressuposto de que apenas uma parte de nós mesmos poderia ser apresentada a indivíduos que frequentamos cotidianamente. Goffman (2002) citava William James para ilustrar essa concepção sociológica:

podemos dizer que ele (o indivíduo) tem praticamente tantas individualidades sociais diferentes quanto são os grupos distintos de pessoas cuja opinião lhe interessa. Geralmente mostra uma faceta diferente de si mesmo a cada um desses diversos grupos. Mais de um jovem, bastante sério, diante de pais e professores, pragueja e faz bravatas como um pirata entre jovens e "insubordinados" amigos. Não nos mostramos a nossos filhos da mesma forma que aos companheiros de clube, aos clientes como aos nossos empregados, aos nossos próprios chefes e patrões, como aos amigos íntimos (James citado por Goffman, 2002, p. 52).

Essas “individualidades" às quais James se refere são fabricadas pelos momentos, ou seja, pelos ajuntamentos presencialmente definidos, supondo um círculo específico e segregado de pessoas. Os indivíduos são, assim, concebidos como seres constituídos de partes que poderiam ser tão numerosas quanto os momentos ou círculos aos quais eles se envolveriam. $\mathrm{O}$

${ }^{10}$ É este enquadramento livremente operado pelo observador que talvez justifique o sucesso performático das selfies, em que a exibição pura e clara do rosto estaria sujeita a diferentes formas de interpretação que representariam, ao mesmo tempo, o rosto de um "filho", "amigo", "parente", "artista" e assim ad infinitum. 
fato é que é justamente essa condição interacional que a forma de comunicação possibilitada pelo Facebook contribui para desfazer. O momento, afinal, perde as suas referências de lugar e, ao perdê-las, os círculos diferenciados são levados a aceitar como conteúdo da interação principalmente o que está sendo publicado pelo indivíduo observado. Os círculos sociais podem aí ser surpreendidos pelo fato de terem acesso a informações sobre um próximo que eles antes não imaginariam. Esta plateia pode, enfim, ver-se diante da revelação de um acontecimento que se desdobra em um lugar ao qual ela mesma não teria imediato acesso, como no "passeio fora da escola" citado por Céu em seu primeiro testemunho. A plateia deve se contentar, então, com uma realidade que repousa sobre as superfícies do aparente, uma vez que não consegue acessar uma realidade composta de elementos que seriam apenas oferecidos pela localidade da interação ${ }^{11}$.

\section{O trunfo da discrição técnica}

O caminho percorrido até aqui teve o Facebook como um espaço disposto a conservar relações educacionais, ainda que contem com uma margem de indefinição derivada das próprias contingências das relações virtuais. Essa condição de aparente normalidade, às vezes, conta com usuários munidos de diferentes interesses que podem ser até mesmo irreconciliáveis uns com os outros: seria o caso de um professor indisposto a manter relações com seus alunos na internet. Esse convívio forçado, às vezes também cordial, provavelmente não seria possível se esse espaço não oferecesse algo de bastante particular e que preferimos chamar aqui de "condições técnicas de discrição". O que a discrição, afinal, teria a ver com as diferentes formas de fazer sociedade no Facebook, ou mais precisamente, com as relações escolares?

Expliquemos. Dostoiévski (2009) via no Palácio de Cristal, edificado em ferro e vidro na ocasião da Exposição Universal de Londres, em 1851, algo que poderia também ser atribuído

\footnotetext{
11 Berger e Luckmann (1967), sobre a mesma esteira, puderam definir uma realidade par excellence fundada também no aqui e no agora, e cujos dados sensíveis, como gesticulações, tons de fala, trocas de olhares, constituem um complexo contexto material envolvendo indivíduos engajados em uma interação. Esses detalhes contribuem com a definição do que se conhece como real. O real, entretanto, pode ser também o virtual, se se concebe que a sensibilidade de Goffman se presta a esclarecer não precisamente o que os indivíduos são, mas o que podem ser de acordo com as margens de manobra possibilitadas pelos momentos que eles estão constantemente produzindo. Goffman, por isso, carrega uma virtualidade sempre latente em sua obra e que, embora não contemplasse uma combinação entre lugar e espaço, previa que qualquer ajuntamento estaria sujeito a receber uma definição mínima da parte dos indivíduos a partir de sentidos e informações igual ou desigualmente distribuídas.
} 


\section{pro.posıções}

http://dx.doi.org/10.1590/1980-6248-2018-0021

\section{$e$-ISSN 1980-6248}

ao Facebook: tratava-se de uma reprovação sobre suas paredes que, transparentes, seriam supostamente capazes de denunciar tudo o que os indivíduos poderiam fazer no seu interior. Essa condição seria semelhante ao princípio da transparência que Breton (2012) mostrou como compatível com a história do desenvolvimento da comunicação via internet. Esse princípio encontraria aderência em grupos de indivíduos tanto tecnófobos quanto tecnófilos, supondo uma sociedade cujas informações jamais escapariam de um grande sistema rastreador. A questão preocupante se torna, portanto, a de saber "quem" operaria esse estranho sistema: enquanto os defensores do mistério, do segredo etc. tenderiam a se opor a ele, outros, defendendo a objetividade e a revelação das coisas, tenderiam a exaltar seu valor.

O que parece sociologicamente interessante se refere aí justamente à ameaça que estes sistemas representariam à autonomia individual. A autonomia, afinal, tenderia a ser subjugada por bancos informacionais que se ocupariam de registrar ações individuais a ponto de tornar seus passos e consequências previsíveis. Os indivíduos, logo, nada teriam a esconder que já não estivesse incorporado a um sistema e - como a impressão de Dostoiévski (2009) sobre o palácio onde não se poderia "mostrar-lhe a língua, nem mesmo às ocultas" - a discrição deixaria de

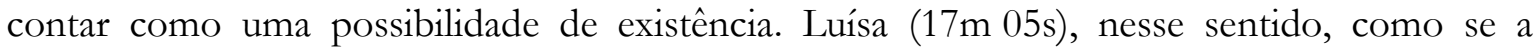
visibilidade escolar operada sobre ela no Facebook fosse algo indesejado, prova certa indecisão a respeito do lugar que seus alunos podem ocupar nessa relação: "não sei o que eu faço... tenho alunos adicionados no meu Facebook, mas não sei se eu separo. Fico sempre com essa dúvida. Porque você fica com a coisa do pessoal, o meu pessoal tá aberto para os alunos também”.

A discrição técnica pode ser sugerida aí como um recurso das interações sociais escolares, entretanto, sempre a depender do uso feito pelos indivíduos. Simmel (2006), especialmente, falou do papel da discrição como aquilo que funcionaria em benefício da manutenção do social, uma aptidão da qual indivíduos lançam mão em vista de definir suas situações diante dos outros. O seu papel, como o "sentido do tato", seria estabelecer "os limites para os impulsos individuais, para a ênfase no eu e para as ambições espirituais e externas, sendo talvez a ação específica que sustente a legitimidade do outro" (Simmel, 2006, p. 66). As habilidades humanas de gestão da distância e da proximidade parecem, então, impossíveis sem técnicas de discrição, ou sem que o Facebook evite que um princípio de transparência se generalize em seu próprio espaço. A polidez, a circunspecção, a discrição, em suma, por que não seriam também uma forma performática de estabelecer uma relação? 


\section{pro.posıções}

http://dx.doi.org/10.1590/1980-6248-2018-0021

Céu, aqui, lançando mão de recursos técnicos, oferece um testemunho cuja discrição aparece de maneira mais evidente. Esta diz respeito à criação de um "duplo", ou seja, de um segundo avatar que, paralelamente, prevê uma relação exclusiva com seu público de alunos em sua página pessoal.

Eu não tinha aluno no meu Facebook, nem no Orkut, não tinha aluno. "Você tem? Não!" porque eu usava para me comunicar com os meus amigos. Aí esse ano, quando eu comecei, três turmas de ensino médio da segunda série aqui, todas, cada uma delas tinha um grupo. Eu vi pelo face da colega que tinha "turma 2008", "turma 2009", "turma 2010". Eu falei "é um canal de comunicação. Vou experimentar". Só que eu fiz um Facebook só para meus alunos. E aí adicionei eles e aí tá funcionando como um canal de comunicação de trabalho, porque a gente se vê uma vez por semana (14m 18s).

A discrição deve ser entendida aqui como um trunfo, e estranho seria não aceitar que diferentes formas de uso são possíveis, seja a partir das funções particulares ao Facebook ou aos dispositivos em que ele se instala. Esse seria o caso de uma mensagem que pode ser lida pelo destinatário sem que seu remetente o saiba - assim como o voyeur que assiste às conversas de um grupo coletivo sem se manifestar, prevendo não estar sendo percebido. A ausência de margens de manobra como essas leva a crer que seria muito mais difícil acolher no Facebook pessoas com as quais guardamos certa reserva (como o fato de acolher aqueles que não são considerados verdadeiros amigos e, assim, reservamos a eles a etiqueta de "censurados"). Os indivíduos discretos, afinal, não são indivíduos ao menos minimamente preocupados com aquilo que os outros possam pensar ou sentir acerca de suas expressões? Essas pessoas é que podem agir silenciosamente, e despercebidamente, como um homem que, desejoso do prazer visual de apreciar corpos femininos na praia, se reserva o direito de dar apenas ligeiros olhares como uma forma de coerção que age sobre a sua vontade ${ }^{12}$.

A discrição como um recurso interacional não é, entretanto, exclusivamente técnica. Solene, por exemplo, em vez de operar seletivamente sobre um possível imenso painel de botões oferecidos pelo Facebook, recorre a soluções mais pessoais, dizendo: "Eu acabo me policiando... porque eu também quero curtir uns besteiroizinhos de vez em quando, e aí eu acabo me privando" (17m 20s). As possíveis impressões que o público escolar pode produzir são aí gestadas por Solene através de suas próprias expressões. Ela, como outros usuários,

$12 \mathrm{O}$ uso da discrição é igualmente uma habilidade comum a batedores de carteira que, de maneira sensível e especializada, realizam furtos sem recorrer ao uso da violência. Os seus furtos, ao não serem violentos, tendem a ser menos traumáticos, e é como forma de proteção do outro que a discrição pode ser vista como virtude até mesmo através de práticas ilícitas ou condenáveis. 
dispensa o uso dos mecanismos automáticos de discrição, estando mais sujeita a procurar resoluções pessoais em sua gestão da distância, sobretudo em se tratando de interações nos espaços mais "públicos” do Facebook.

No quadro abaixo são apresentados três espaços de comunicação: o "público", o "coletivo" e o "privado", que pertencem ao espaço maior do Facebook. As condições técnicas de discrição podem ser mensuradas a partir do número de mecanismos que transmitem informações automáticas sobre as interações. Estes se distribuem desigualmente entre estes espaços, que condicionam, assim, maior ou menor trocas automáticas de informação entre os indivíduos. A sua distribuição é mais efetiva em espaços como "caixas de mensagens", que, por sua vez, supõem uma relação menos de "um-para-vários" que "um-para-outro". As caixas de mensagem geralmente supõem relações personalizadas, já que esse "outro" representa alguém particularmente significativo.

\section{Quadro 1 - Espaços do Facebook seguidos de variações acerca das condições técnicas de discrição}

\begin{tabular}{|l|l|l|l|l|}
\hline \multicolumn{2}{|c|}{} & \multicolumn{2}{|c|}{ Expressão } & \multicolumn{2}{c|}{ Impressão } \\
\cline { 2 - 5 } \multicolumn{2}{|c|}{ Espaço } & $\begin{array}{l}\text { Horário da } \\
\text { mensagem enviada }\end{array}$ & $\begin{array}{l}\text { Mensagem recebida } \\
\text { e visualizada }\end{array}$ & $\begin{array}{l}\text { Horário da mensagem } \\
\text { visualizada }\end{array}$ \\
\hline Público & Mural & Sim & Não & Não \\
\hline Coletivo & Grupo & Sim & Sim & Não \\
\hline Privado & Caixa & Sim & Sim & Sim \\
\hline
\end{tabular}

Este quadro permite observar também como as expectativas de reciprocidade variam entre os espaços, ou seja, quanto mais os espaços são compostos por mecanismos de transparência (como no espaço privado), mais eles tendem a testar a sintonia entre os contatos. A existência de uma transparência técnica é justamente o que condicionaria a seguinte pergunta: "por que você não respondeu minha mensagem, uma vez que sei que você a recebeu e a visualizou?" Os indivíduos alinhados uns aos outros, afinal, nada tenderiam a esconder, de modo que a transparência dos espaços privados não seria vista como um problema ao colocar ininterruptamente à prova a autenticidade de suas relações. 


\section{pro.posıções}

http://dx.doi.org/10.1590/1980-6248-2018-0021

$e$-ISSN 1980-6248

Este alinhamento performático, entretanto, baseia-se também em "não ditos", segredos que convêm ser guardados pela própria discrição do Facebook, conforme mensagem automática abaixo que, entre outras, são eventualmente informadas aos seus usuários:

Figura 1 - Duas sinalizações do “Time” responsável pela privacidade no Facebook seguida de tradução do autor
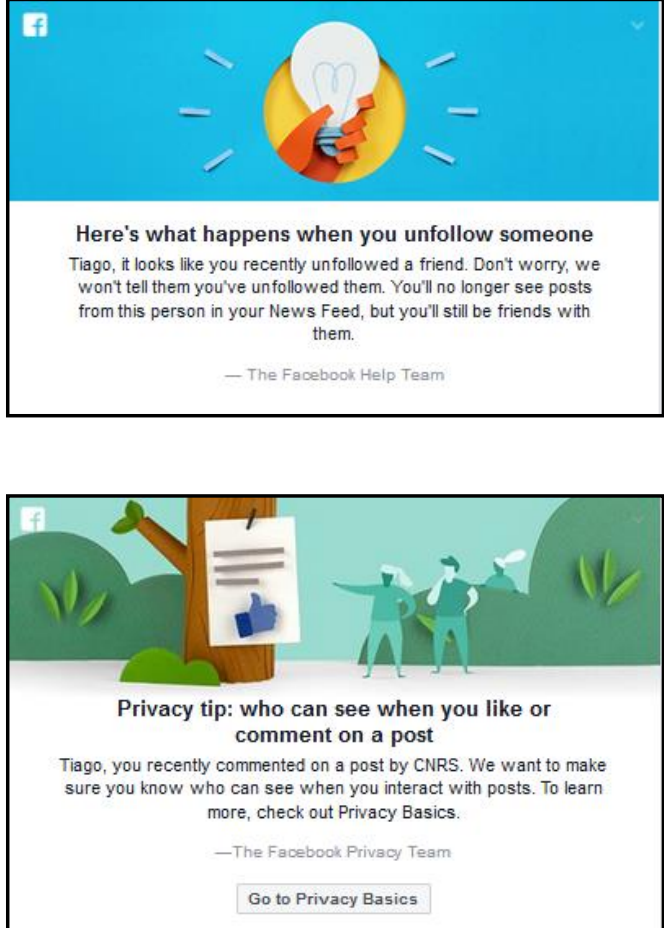

Saiba o que acontece quando você deixa de seguir alguém

[Caro usuário], parece-nos que recentemente você deixou de seguir um amigo seu. Não se preocupe. Nós não contaremos isso a ele. Você não verá mais postagens desta pessoa em sua página pessoal, mas você permanecerá amigo dele.

- Equipe de Ajuda do Facebook

Fonte: página pessoal de Facebook dos autores.

Estes lembretes, como formas técnicas de conservação da privacidade, embora em maior ou menor medida assegurem uma relação de distância entre os usuários, também podem se tornar obsoletos quando os professores se encontram em um quadro de reinvindicações identitárias. Os professores podem, afinal, encontrar-se na aceitável condição de considerar que nada têm a esconder - inclusive seus "besteiroizinhos" -, conforme o exemplo a seguir, de Mariana. O Facebook, deste modo,

é uma oportunidade que a gente tem e a gente não pode perder a oportunidade de ensinar os nossos alunos e enfim, todo mundo, a ser respeitado pelo que a gente é. Eu não vejo essa diferença... assim... eu não sou "a professora" e "a não professora". Eu sou eu, Mariana. E eu sou! Entende? (17m 38s).

\section{Dica de privacidade: quem pode ver quando você curte ou comenta uma \\ Caro usuário], recentemente você uma publicação do Conselho assegurar de que você sabe quem vê quando você interage em uma postagem. Básicas de Privacidade. \\ - Equipe de Privacidade do Facebook}




\section{pro.posıções}

http://dx.doi.org/10.1590/1980-6248-2018-0021

\section{$e$-ISSN 1980-6248}

A exigência de um valor em comum - o "respeito" a que Mariana se refere - poderia ser traduzido em termos de uma formação social, como um "time" (Goffman, 1959) em que os integrantes são solidários uns com os outros. Mariana reivindica aí novos pares - seus alunos convidados a aderir a um princípio comum de coesão social. O conto "A perda da auréola", de Baudelaire (1996), é instrutivo com relação ao testemunho de Mariana. Este contém uma situação em que dois personagens se encontram na entrada de um manvais lieu (um lugar mal-frequentado), como se insinuasse se tratar de um bordel. O fato é que, para um deles, o encontro é tido como uma surpresa: “O quê, você por aqui?” E o outro, por sua vez, procura amenizar, reivindicando seu direito de ser só mais um e de assim poder se "entregar à devassidão, como os simples mortais". Este gostaria, enfim, de frequentar a noite como se se tratasse de alguém que passasse sem ser percebido, valorizando em certa medida o papel do anonimato.

Baudelaire parece representar tanto zonas obscuras de desejos que poderiam residir em inesperados indivíduos quanto uma exigência de discrição que seria inerente à modernidade. A discrição seria uma forma de desviar os olhos dos observadores dispostos a fazer definições objetivas. Essa condição apenas seria possível à medida que seu observador fizesse tábula rasa das "insígnias" do protagonista, tornando comum e aceitável o fato de frequentar um manvais lieu graças ao "time" que ambos formariam. A discrição reivindicada pelo protagonista-observado pode ser considerada, então, como uma forma de levar vantagem sobre os olhos do observador, que se solidariza com seu observado, reequilibrando um jogo interacional.

Por isso, as interações no Facebook não fogem à regra de uma relação dramática entre o eu e o outro. Goffman provavelmente não seria contrário a uma inflexão em seu quadro de análise, uma vez que aquilo que considerou como estabelecimentos físicos ou lugares poderiam ser acrescidos da noção de espaço à medida que um vai e vem de impressões e expressões permanecem atuantes. Goffman, entretanto, jamais falou de "mecanismos técnicos de discrição", mas, sim, da circunspeção, da disciplina, do espírito de equipe de um grupo. O fato é que nos "espaços" a discrição não deixa de ser altamente condicionada pelos dispositivos técnicos - como seria na vida cotidiana o uso de aparelhos como binóculos, espelhos ou buracos de fechadura. 


\section{pro.posıções}

http://dx.doi.org/10.1590/1980-6248-2018-0021

\section{$e$-ISSN 1980-6248}

\section{Considerações finais}

A análise aqui realizada, particularmente, pressupôs uma relação dinâmica entre "lugar" e "espaço", com o objetivo de sublinhar o estado de dissituação local que promove interações entre indivíduos às vezes em pleno estado de mobilidade: viajando, trabalhando, comendo, descansando etc. Esta dissituação é que permitiu avançar em direção ao arranjo do "ajuntamento de círculos sociais diferenciados" que contrasta com outras formas de sociabilidades cotidianas: reuniões, cerimônias, encontros, aulas etc. Este ajuntamento pode ser considerado uma razão maior da aventura a qual os professores provam no Facebook através das injunções de gestar uma relação de proximidade e de distância com círculos sociais que antes se encontravam segregados (porque localmente situados).

A peculiaridade do Facebook esteve, então, em formar uma comunicação de "um-paravários" de modo que as interações contaram com um vai e vem constante de expressões e impressões comumente diferenciadas. Goffman (2002), por sua vez, conferia à noção de gestão da impressão - impression management - uma forma de exercício da autonomia, à medida que supunha um indivíduo capaz de definir a si mesmo graças ao controle que ele exerceria sobre o olhar do outro. O olhar do outro no Facebook é ainda, virtualmente, um olhar heterogêneo, e é por isso que uma inflexão na perspectiva do sociólogo se torna possível. Este seria o caso de privilegiar uma análise não sobre a manipulação da impressão do outro, mas sobre a gestão da expressão de si mesmo, revelando práticas de antecipação de impressões induzidas pelos mecanismos de transparência.

A relação entre uma sociologia alvorada na segunda metade do século XX e um problema educacional do século XXI talvez apenas seja possível graças às rearticulações conceituais, condicionando, então, certa renovação científica. A sociologia da educação contemporânea, por sua vez, tem a tarefa de colocar em análise, valorizando-os, atuais componentes sociais que fazem das relações de proximidade e de distância um objeto digno de atenção científica. A ausência, por exemplo, de uma história da educação atenta ao mesmo objeto seguramente torna esse empreendimento mais árduo, mas não impossível, uma vez que fontes empíricas sobre a gestão da imagem de professor podem ser encontradas em registros etnográficos, cinematográficos e jornalísticos. Estes materiais talvez condicionem sondagens em que as relações de proximidade e distância digam algo também sobre o carisma, a autoridade e a credibilidade envolvidas no papel de professor. 


\section{pro.posıções}

http://dx.doi.org/10.1590/1980-6248-2018-0021

\section{$e$-ISSN 1980-6248}

A análise das relações de proximidade e de distância ora nada tem a ver com pressupostos morais que enquadrariam as relações pedagógicas dentro de certos limites. O que importa é saber como estas relações seriam possíveis sem que elas mesmas caíssem em descrédito. O que para um professor representaria uma relação de distância sem inacessibilidade, para outro poderia se tratar de uma relação de proximidade sem intimidade, mantendo ambos os laços pedagógicos plausíveis. A fatalidade de uma relação pedagógica caída em descrédito, estremecida temporalmente, por força de um mal-entendido na internet, tão logo requereria uma sociologia do cotidiano educacional capaz de analisar não apenas tensões, mas também resoluções pessoais ou institucionais que reestabeleceriam, provavelmente, a ordem das interações entre professores e alunos.

Grato a Luiz G. Augsburger pela leitura preliminar e diligente deste artigo.

\section{Referências}

Aspling, F. (2011). The private and the public in online presentations of the self: a critical development of Goffman's dramaturgical perspective. Dissertação de Mestrado, Stockholms universitet, Stockholm.

Baudelaire, C. (1996). Pequenos poemas em prosa: edição bilíngue (Trad. Dorothée de Bruchard). Florianópolis: Editora da UFSC.

Benelli, S. J. (2003). O internato escolar "O Ateneu”: produção de subjetividade na instituição total. Psicologia USP, 14(3), 133-170. doi:10.1590/S0103-65642003000300011

Berger, P. L., \& Luckmann, T. (1967). The social construction of reality: a treatise in the sociology of knowledge. New York: Archor Books.

Breton, P. (2012). Le culte de l'internet: une menace pour le lien social? Paris: La découvert.

Burns, T. (1992). Erving Goffman. London: Routledge.

Carrano, P. (2013, 25 de julho). Uma escola entre redes: documentário de pesquisa [Postagem on-line]. Recuperado de http://www.emdialogo.uff.br/content/uma-escola-entreredes-sociais-documentario-de-pesquisa

Casilli, A. (2010). Les liaisons numériques: vers une nouvelle sociabilité? Paris: Éditions du Seuil. 


\section{pro.posıções}

http://dx.doi.org/10.1590/1980-6248-2018-0021

\section{$e$-ISSN 1980-6248}

DaMatta, R. (1997). Carnavais, malandros e heróis: para uma sociologia do dilema brasileiro (6a ed.). Rio de Janeiro: Rocco.

Dostoievski, F. (2009). Memórias do subsolo (Trad. Boris Schnaiderman, 6a ed.). São Paulo: Editora 34.

Durkheim, E. (1938). L'évolution pédagogique en France: des origines a la renaissance. Paris: Librarie Félix Alcan.

Elias, N. (1994). A sociedade dos indivíduos (Trad. Vera Ribeiro). Rio de Janeiro: Zahar.

Freund, C., \& Biar, L. (2017). Gerenciando o estigma do professor contratado: uma análise de discurso crítica. Educação em Revista, 33, e166838. doi:10.1590/0102-4698166838

Giddens, A. (1996). The consequences of modernity. Cambridge: Polity.

Goffman, E. (1959). The presentation of self in everyday life. New York: Archor Books.

Goffman, E. (2002). A representação do eu na vida cotidiana. Petrópolis: Vozes.

Guigue, M., \& Boulin, A. (2016). L'internat scolaire: limites et paradoxes d'une institution totale. Educação e Realidade, 41(4), 985-1002. doi:10.1590/2175-623661105

Isaac, M., \& Ember, S. (2016, 29 de junho). Facebook to change news feed to focus on friends and family. The New York Times. Recuperado de http://www.nytimes.com/2016/06/30/technology/facebook-to-change-news-feedto-focus-on-friends-and-family.html?_r=2

Jacobsen, H. M., \& Kristiansen, S. (2014). The social thought of Erving Goffman. Sage: London. Manning, P. (1992). Erving Goffman and modern sociology. Cambridge: Polity Press.

Martuccelli, D. (1999). Sociologies de la modernité: l'itinéraire du XXe siècle. Paris: Gallimard.

Moulin, L. (1994). A vida quotidiana dos estudantes na Idade Média. Lisboa: Livros do Brasil.

Presos fingem ser médicos, ligam e pedem dinheiro para exames. (2017, 27 de julho). Jornal nacional. Recuperado de http://g1.globo.com/jornal-nacional/noticia/2017/07/presosfingem-ser-medicos-ligam-e-pedem-dinheiro-para-exames.html

Professora é demitida por não excluir alunos do Facebook. (2017, 10 de setembro). O globo. Recuperado de https://oglobo.globo.com/sociedade/tecnologia/professora-demitidapor-nao-excluir-alunos-do-facebook-12136971 


\section{pro.posıções}

http://dx.doi.org/10.1590/1980-6248-2018-0021

$e$-ISSN 1980-6248

Projeto de Lei 995/2015. (2015). Acrescenta dispositivo à Lei no 12.965, de 23 de abril de 2014, que estabelece princípios, garantias, direitos e deveres para o uso da Internet no Brasil. Recuperado de http://bit.ly/36uLHKE

Rouche, M. (1981). Histoire génerale de l'enseignement et de l'éducation en France: des origines à la Renaissance: Ve siécle av. J.-C. - XVe siècle (Vol. 1). Paris: Perrin.

Schilling, F., \& Miyashiro, S. G. (2008). Como incluir? O debate sobre o preconceito e o estigma na atualidade. Educação e Pesquisa, 34(2), 243-254. doi:10.1590/S151797022008000200003

Simmel, G. (2006). Questões fundamentais de sociologia: indivíduo e sociedade (Trad. Pedro Caldas). Rio de Janeiro: Zahar.

Smith, G. (2006). Erving Goffman. Routledge: London.

Weber, M. (2013). Ciência como vocação. In A. Botelho (Org.), Essencial sociologia (pp. 392-431). São Paulo: Companhia das Letras.

Submetido à avaliação em 07 de março de 2018; revisado em 11 de julbo de 2018; aceito para publicaşão em 16 de marco de 2019. 